Anuario da Facultade de Dereito da Universidade da Coruña

Vol. 20 (2016), pp. 526-531

ISSNe: 2530-6324 || ISSN: 1138-039X

DOI: https://doi.org/10.17979/afdudc.2016.20.0.1955

\title{
EL CRÉDITO RESPONSABLE ${ }^{1}$
}

\author{
NOELIA COLLADO-RODRÍGUEZ \\ Contratada Predoctoral FPI. \\ Grupo de Investigación "Empresa, Consumo y Derecho" \\ Universidade da Coruña.
}

Resumen: El principio de crédito responsable se manifiesta a través de una serie de conductas recogidas en las Directivas 2008/48/CE de crédito al consumo, y 2014/17/UE de crédito hipotecario. Sin embargo, el contenido del principio difiere de una Directiva a otra. En la Directiva 2008/48/CE observamos un enfoque reducido del principio, mientras que en la Directiva 2014/17/UE, el contenido se amplía incluyendo un mayor número de conductas.

Palabras clave: crédito responsable; crédito al consumo; crédito hipotecario; protección del consumidor; Derecho de consumo.

Abstract: The responsible lending principle is stated through an array of conducts contained in the Consumer Credit Directive, and in the Mortgage Credit Directive. However, the content of the principle is different in each one. The Consumer Credit Directive shows a reduced perspective of the principle, whereas the Mortgage Credit Directive contains a wider perspective of it.

Keywords: responsible lending; consumer credit; mortgage credit; consumer protection; consumer law.

\footnotetext{
${ }^{1}$ Versión escrita de la comunicación oral presentada en las "VII Jornadas de Derecho de Consumo: Mecanismos de Protección del Consumidor de Crédito", celebradas en la sede del Colegio de Abogados de A Coruña los días 12 y 13 de noviembre de 2015. Y, organizadas por la Universidade da Coruña y el Ilustre Colegio de Abogados de A Coruña. Este trabajo forma parte de los resultados del Proyecto de Investigación "La evaluación de la solvencia del consumidor de crédito: un nuevo modelo de protección en el Derecho de consumo europeo" (DER2013-47711-P), financiado por el Ministerio de Economía y Competitividad.
} 
SUMARIO: I. INTRODUCCIÓN. II. ORIGEN Y EVOLUCIÓN. III. CRÉDITO RESPONSABLE COMO PRINCIPIO. IV. CONCEPTO DE CRÉDITO RESPONSABLE. V. CONCLUSIÓN.

\section{INTRODUCCIÓN}

Durante los últimos años hemos asistido al origen y rápida popularización del concepto de crédito responsable en el ámbito comunitario, que surge como un instrumento de prevención del sobreendeudamiento y que, con el advenimiento de la crisis económica y financiera, además de la influencia de las nuevas corrientes de la economía conductista, adquiere una mayor dimensión. El fracaso del sistema tradicional de protección al consumidor sustentado sobre la obligación de información ${ }^{2}$, ha dado lugar a que el crédito responsable se erija como un pilar fundamental en la protección del consumidor de crédito, provocando un cambio de paradigma en la manera en que éste ha de protegerse.

\section{ORIGEN Y EVOLUCIÓN}

Los antecedentes del principio de crédito responsable podemos situarlos en las legislaciones de algunos Estados miembros, como Suecia ${ }^{3}$, Bélgica ${ }^{4}$ y Suiza ${ }^{5}$, a través, principalmente de la evaluación de la solvencia del consumidor.

A nivel comunitario, por su parte, adquiere rango legal en la Directiva 2008/48/CE de Crédito al Consumo, si bien en las primeras versiones de esta Directiva el concepto de crédito responsable quedaba recogido de manera expresa.

La otra norma donde se recoge el principio de crédito responsable es en la Directiva 2014/17/UE ${ }^{6}$, comúnmente denominada Directiva de crédito hipotecario. En ésta última, las normas en que se concreta el principio de crédito responsable se incorporan de una manera más completa y precisa que en la Directiva de Crédito al Consumo. Esto se debe a la diferencia entre la importancia que, para el consumidor y para el mercado, existe entre el crédito al consumo y el crédito hipotecario. Cuestión que justifica una mayor concreción del principio de crédito responsable en la Directiva de crédito hipotecario respecto de la Directiva de crédito al consumo ${ }^{7}$.

\footnotetext{
${ }^{2}$ Vid. BEN-SAHAR, O.; SCHNEIDER, C. E.: "The failure of mandated disclosure" en 159 University of Pennsylvania Law Review 647. Especialmente páginas 679 y ss.

${ }^{3}$ En la Ley sueca de Crédito al Consumo (Konsumentkreditlagen 1992:830) y en su Ley Bancaria (Bankrörelselagen 1987:617). Vid. REIFNER, U.; KIESILAINEN, J.; HULS, N.; SPRINGENEER, H.: “Consumer Overindebtedness and Consumer Law in the European Union”. Septiembre 2003. Página 100.

4 En la «Loi relative au crédit à la consommation» de 12 de junio de 1991.

${ }^{5}$ En la "Loi fédérale sur le crédit à la consommation" de 23 de marzo de 2003.

${ }^{6}$ Directiva 2014/17/UE del Parlamento Europeo y del Consejo de 4 de febrero de 2014 sobre los contratos de crédito celebrados con los consumidores para bienes inmuebles de uso residencial.

${ }^{7} \mathrm{Cfr}$. Considerando $22^{\circ}$ de la Directiva de crédito hipotecario.
} 


\section{CRÉDITO RESPONSABLE COMO PRINCIPIO}

A pesar de que en un primer momento se mencionaba con carácter expreso en algunas de las propuestas modificadas de la Directiva de Crédito al Consumo ${ }^{8}$, finalmente, el principio de crédito responsable no aparece explicitado como tal principio en ninguna de las Directivas mencionadas.

Podemos, sin embargo, inferir la condición de principio del concepto de crédito responsable debido a que tanto en los trabajos preparatorios ${ }^{9}$, como en los Considerandos de ambas Directivas ${ }^{10}$, se anuncia como criterio informador que inspira la legislación. Y, como criterio que informa la legislación, la vigencia del principio de crédito responsable se manifiesta a través de la imposición de determinadas conductas en sendas Directivas. No obstante, para identificar qué conductas recogidas en las Directivas señaladas son aquellas dimanantes del principio de crédito responsable, hemos primero de señalar qué entendemos como tal.

\section{CONCEPTO DE CRÉDITO RESPONSABLE}

Tras la lectura y análisis de ambas Directivas, así como de los trabajos preparatorios de cada una de ellas, podemos concluir que, aun teniendo ambas una batería de medidas - en mayor o menor medida - similar, el enfoque que se desprende de cada Directiva es diferente, pudiendo distinguirse un enfoque amplio y otro reducido del principio de crédito responsable ${ }^{11}$.

En la Directiva 2008/48/CE de contratos de crédito al consumo observamos un enfoque reducido de lo que se entiende por crédito responsable, que se circunscribe a conductas en el ámbito contractual y puede definirse como un principio jurídico que

\footnotetext{
${ }^{8}$ Vid. Propuesta de Directiva de crédito al consumo de 2002; Propuesta modificada de Directiva de crédito al consumo de 2004; y, Propuesta modificada de Directiva de 2005.

${ }^{9}$ Que, en el caso de los trabajos preparatorios de la Directiva de crédito al consumo, explícitamente hablan de principio de crédito responsable. En el caso de la Propuesta de Directiva de 2002 lo recoge en el Cdo. 15\% ; y, en el caso de las Propuestas modificadas de 2004 y 2005, ambas lo recogen en su artículo 6.

${ }^{10}$ En la Directiva de crédito al consumo, concretamente en el Cdo 26 $26^{\circ}$, dice: "Los Estados miembros deben tomar las medidas adecuadas para promover unas prácticas responsables en todas las fases de la relación crediticia [...]. En un mercado crediticio en expansión, en particular, es importante que los prestamistas no concedan préstamos de forma irresponsable o sin haber evaluado previamente la solvencia del consumidor". En la Directiva de crédito hipotecario, por su parte, puede observarse la relevancia de este principio a lo largo de toda la motivación de la Directiva, especialmente en los Cdos. $3^{\circ}, 4^{\circ}$ y $5^{\circ}$.

${ }^{11}$ Podemos encontrar en la doctrina referencias a esta dualidad de enfoques del crédito responsable. Como CUENA CASAS, quien explica que "el préstamo - o crédito - responsable puede referirse en un sentido amplio a toda normativa de protección del cliente bancario, obligaciones de transparencia de la entidad financiera que se traduce en deberes de información precontractual [...], la adecuación de los contratos planteados con los intereses, necesidades y situación financiera del cliente concreto [...] o bien, de forma más restringida, a la obligación de evaluar la solvencia del deudor de manera que se conceda el préstamo a quien es capaz de devolverlo según lo pactado". CUENA CASAS, M.: "El sobreendeudamiento privado como causa de la crisis financiera y su necesario enfoque multidisciplinar" en Préstamo Responsable y Ficheros de Solvencia. PRATS ALBENTOSA, A.; CUENA CASAS, M. (Coordinadores). Aranzadi. Cizur Menor. 2014. Página 64.
} 
impone conductas tanto al prestamista como al prestatario, con el objetivo de que el consumidor adquiera productos crediticios que el consumidor/prestatario sea capaz de afrontar económicamente. Ello se justifica en que, tanto en el Cdo. $26^{\circ 12}$ como en los trabajos preparatorios de la Directiva, el crédito responsable se ha identificado en todo momento con la obligación de evaluar la solvencia del consumidor - Propuesta de Directiva de 2002, 2004 y 2005 -, y en las Propuestas modificadas de Directiva de 2004 y 2005, además se identifica con otras $\operatorname{conductas}^{13}$ de carácter contractual y que persiguen el objetivo antedicho de que el consumidor adquiera productos crediticios que puede permitirse.

Las obligaciones contenidas en la Directiva 2008/48/CE, sobre las que se elabora este concepto «reducido» son:

En primer lugar, la obligación de evaluar la solvencia del consumidor (art. 8). A pesar de que puede afirmarse que se trata de una herramienta obvia para el buen curso de la actividad bancaria, lo cierto es que ha tenido que ser recogida legalmente debido al incumplimiento sistemático de las más elementales normas de prudencia ${ }^{14}$. El objetivo es evitar que se concedan préstamos a consumidores cuyas circunstancias hagan suponer que no será capaz de devolver, previniendo así situaciones de sobreendeudamiento. Para ello, el prestamista deberá de evaluar la capacidad crediticia de prestatario con arreglo a la información suministrada por el prestatario y la consulta de la base de datos pertinente. Si bien es cierto que la obligación de evaluar la solvencia del consumidor constituye una conducta clave del principio de crédito responsable, la manera en que se halla recogida no está exenta de toda crítica. La primera crítica sería que la consulta de las bases de datos no tenga carácter obligatorio y el prestamista pueda dejar en manos del consumidor el suministro de la información necesaria para la evaluación de la solvencia. Otra crítica es que no se establezca la obligación de evaluar la solvencia de los avalistas del contrato de crédito, ya que el incumplimiento de la obligación tiene una repercusión directa sobre estos que en un momento determinado pueden resultar obligados al pago de las obligaciones derivadas del contrato de crédito. Por lo que tan importante es evaluar la solvencia del prestatario, como la de los avalistas.

En segundo lugar, la obligación de proporcionar explicaciones adecuadas acerca de la información suministrada (art. 5.6). Esta obligación supone el reconocimiento de que el consumidor puede no leer, entender o gestionar la información suministrada por lo que es necesario que se obligue a los prestamistas y asimilados a explicar ciertos aspectos esenciales del producto crediticio. Va más allá de ser una mera puesta a disposición de la información que permite al consumidor hacerse una representación de las consecuencias derivadas de la conclusión del contrato.

En tercer lugar, la evaluación por parte del consumidor de la idoneidad del

\footnotetext{
${ }^{12}$ Que se refiere la importancia de "que los prestamistas no concedan préstamos de forma irresponsable o sin haber evaluado previamente la solvencia del prestatario".

${ }^{13}$ Como la obligación de suministrar la información precontractual y la obligación de asesoramiento, que en la Propuesta de 2005 se sustituye por la obligación de prestar las explicaciones adecuadas al consumidor.

${ }^{14}$ En este sentido Cfr. CUENA CASAS, M.: "Préstamo responsable, información crediticia y protección de datos personales" en Revista de Derecho Concursal y Paraconcursal. Anales de Doctrina, Praxis, Jurisprudencia y Legislación. №20. 2014. Página 7 del documento PDF.
} 
contrato (art. 5.6). Se recoge de manera conjunta con la obligación del prestamista de suministrar explicaciones adecuadas, ya que el consumidor debe tomar estas explicaciones en consideración para realizar el denominado test de idoneidad. Se pretende así que el consumidor tome su parte de responsabilidad en la elección del producto crediticio haciendo un esfuerzo en asimilar, sino la información, las explicaciones del prestamista o, intermediario de crédito, para tomar una decisión razonada.

En cuarto y último lugar, el suministro al prestamista, por parte del prestatario, de la información necesaria para la correcta evaluación de la solvencia. En el contrato de crédito, la asimetría de la información presente en las relaciones de consumo es doble $^{15}$, ya que no sólo el consumidor está en posición del inferioridad respecto al empresario en cuanto a la información sobre el mercado de crédito, sino que el prestamista también se halla en posición de inferioridad respecto al consumidor ya que no conoce, a priori, la situación económica de éste y no sabe, además, si tiene capacidad económica suficiente para devolver el importe total del préstamo. Para actuar en consonancia con la adquisición responsable de crédito, el consumidor debe ser diligente en la entrega de la información relativa a su situación económica y así lograr una evaluación de la solvencia precisa.

No obstante lo anterior, la Directiva 2014/17/UE nos ofrece un enfoque distinto del crédito responsable. A pesar de que la Directiva de crédito hipotecario recoge también las conductas que acabamos de mencionar (arts. 18, 16 y 20) y de las que inferimos la vigencia del principio que nos ocupa en el marco de la Directiva 2008/48/CE, en la Directiva 2014/17/UE evitar la concesión irresponsable de créditos constituye uno de los fundamentos de la Directiva. Esto parece desprenderse de los Cdos. $2^{\circ}$ a $6^{\circ}$ de la Directiva, en los que la irresponsabilidad en la concesión de créditos - Cdos. $3^{\circ}$ y $4^{\circ}$ - es la idea central que determina, junto a la pretensión de la creación de un mercado interior, la publicación de la Directiva con el propósito de crear un mercado interior más transparente y eficiente $-\mathrm{Cdos} .2^{\circ}$ y $6^{\circ}-$. Atendiendo a esta motivación, se infiere que casi la totalidad de las conductas recogidas en la Directiva de crédito hipotecario tienen como objetivo promover la concesión responsable de crédito, ampliándose así, de manera considerable el concepto de crédito responsable. En consecuencia, el principio de crédito responsable en sentido amplio incluye medidas de educación a los consumidores - art. 6 -; normas reguladoras de la actuación de prestamistas, intermediarios de crédito y representantes designados - arts. 7 a 9 -, así como medidas de supervisión y control de estos operadores y de entidades no crediticias - 29 a 36 -, incluso de vigilancia de los mercados - art. 26 -; obligaciones relativas a la información al consumidor - arts. 10,11, 13, 14, 15, 16 y 27-; la evaluación de la solvencia del consumidor - arts. 18 a 21 -; normas reguladoras del servicio de asesoramiento - art. 22 -; derecho de reembolso anticipado del crédito - art. 25 -; y, por último, insta a los Estados miembros a que establezcan medidas que alivien al consumidor en el caso de demora o ejecución hipotecaria, en sentido de que los prestamistas agoten todas las vías posibles antes de instar la ejecución - art. 28 -.

De acuerdo con este enfoque, el crédito responsable es aquel principio que persigue que, durante la preparación, perfección y vigencia del contrato de crédito, tanto

\footnotetext{
${ }^{15}$ Vid. ÁlVAREZ LATA, N.: "Comentario del artículo 11" en Comentarios a la Ley de Crédito al Consumo. MARÍN LÓPEZ, M.J. (Director). Aranzadi. Cizur Menor. 2014. Página 525.
} 
el prestamista como el prestatario observen una conducta diligente y transparente. Si nos detenemos ante esta definición de lo que entendemos por crédito responsable en su enfoque amplio, puede observarse su coincidencia con uno de los objetivos de la Directiva: "la instauración de un mercado crediticio más transparente y eficiente" Este sería otro motivo más para afirmar que el principio de crédito responsable subyace en el texto de la Directiva, erigiéndose en criterio informador de las normas contenidas en ella.

Este enfoque más amplio que se desprende de la Directiva 2014/17/UE, puede observarse también en numerosos informes emanados de diferentes instituciones como el Banco Mundial ${ }^{17}$, la Federación Hipotecaria Europea ${ }^{18}$, así como varias organizaciones de protección al consumidor de crédito $^{19}$, incluso la propia Comisión Europea $^{20}$ - . Estos documentos contienen "recomendaciones" en torno a lo que debe entenderse o cómo debe funcionar el crédito responsable. Estas recomendaciones pueden agruparse siete líneas de actuación principales: una regulación completa $\mathrm{y}$ comprehensiva; la supervisión y control de las entidades crediticias; la publicidad e información precontractual: la evaluación de la solvencia; la obligación de asesoramiento, la educación de los consumidores; y la resolución de conflictos. Recomendaciones que coinciden con muchas de las medidas recogidas en la Directiva 2014/17/UE.

\section{CONCLUSIÓN}

La vigencia del principio de crédito responsable se manifiesta a través de las normas contenidas en las Directivas 2008/48/CE y 2014/17/UE. Sin embargo, no podemos afirmar que el contenido del principio sea el mismo en sendas Directivas, sino que puede apreciarse una dualidad de enfoques: uno más amplio en la Directiva de crédito hipotecario, y otro más reducido en la Directiva de crédito al consumo. No obstante lo anterior, independientemente del enfoque utilizado a la hora de abordar el principio de crédito responsable, podemos afirmar que el fin último que subyace de aquel es la prevención del sobreendeudamiento del consumidor.

\footnotetext{
${ }^{16}$ Vid. cdo. $2^{\circ}$. Y, en el mismo sentido, vid. Cdo. $6^{\circ}$.

${ }^{17}$ Vid. "Responsible Lending. Overview of Regulatory Tools". Banco Mundial. Octubre de 2013.

18 Vid. "Proposal for EU Responsible Lending standards for home loans". European Mortgage Federation. Mayo de 2009.

${ }^{19}$ Vid. "FinCoNEt report on Responsible Lending: Review of supervisory tools for suitable consumer lending practices" The International Financial Consumer Protection Organisation (FinCoNet). Julio de 2014. Y, "Responsible Lending: An international Landscape". Consumers International. Noviembre de 2013.

${ }^{20}$ Nos referimos a las medidas propuestas en el Libro Blanco sobre la Integración del Mercado Hipotecario de 18 de diciembre de 2007.
} 